\title{
VIOLATION OF PRIVACY IN MIGRATION CONTROL DECREASES CITIZENS' LIBERTIES AND PUBLIC ACCOUNTABILITY
}

\author{
Aleksandra Samonek \\ http://orcid.org/0000-0002-3104-4415 \\ Université catholique de Louvain \\ Jagiellonian University, Kraków
}

\begin{abstract}
In this paper I explore the influence of the state's approach to foreigners (migrant or nonmigrant) on the rule of law within the receiving country, limiting my considerations to the problem of protecting the right to privacy. My key argument is that normalizing infringement on the privacy of foreigners, for example due to a certain recurrent 'state of emergency', leads to weakening of the execution of privacy protection by means of ground-level regulations. I begin by analyzing the difference between the right to privacy and privacy laws, and proceed to make this difference clearer by analyzing the foundations of privacy protection in two distinct legal systems, i.e. that of Poland and the USA. Then, I present the similarities and differences in treating the foreigners and the citizens of a country using the example of mass surveillance. These observations lead to proposing an answer to the following question: why are foreigners treated differently in the context of privacy? Finally, I describe the nature of the aforementioned 'state of emergency' and get into more detail on the relationship between security and privacy infringement. The key point of this paper will be made by describing the process of weakening the citizens' privacy protection by using the regulations and technology developed for the sake of alleviating the 'state of emergency' related to the foreigners.
\end{abstract}

Keywords: privacy, privacy infringement, migration control, human rights, democracy, security.

\section{INTRODUCTION}

In this paper I explore the influence of the treatment of foreigners by the state on the rule of law within the receiving country, limiting my considerations to the problem of protecting the right to privacy. My principal argument is that normalizing 
infringement on the privacy of foreigners, for example due to a certain recurrent "state of emergency," leads to weakening of the execution of privacy protection by means of ground-level regulations.

The following section is dedicated to explicating the difference between the right to privacy and privacy laws. Then I proceed to make this difference clearer by analyzing the foundations of privacy protection in two distinct legal systems, i.e. that of Poland and the USA. Then I will present the similarities and differences in treating the foreigners and the citizens of a country using the example of mass surveillance. These observations lead me to proposing an answer to the question: why are foreigners treated differently in the context of privacy?

Finally, I shall describe the nature of the aforementioned "state of emergency" and get into more detail on the relationship between security and privacy infringement. The key point of this paper is made by describing the process of weakening the citizens' privacy protection by using the regulations and technology developed for the sake of alleviating the "state of emergency" related to the foreigners.

\section{THE RIGHT TO PRIVACY V. PRIVACY LAWS}

When discussing the issues of privacy, we must recognize the difference between the right to privacy and privacy laws. When referring to the right to privacy we shall mean a fundamental human right protected under Article 8 of the European Convention on Human Rights (ECHR). Article 8 of the ECHR defines the right to privacy as a universal right to respect for private and family life, home and correspondence. It also imposes a limitation on the interference of the public authority to cases where both following conditions are satisfied:

(1) there exists a law which permits the interference, and

(2) the interference is necessary in a democratic society in the interest of national security, public safety or the economic well-being of the country, prevention of disorder or crime, protection of health and morals, or for the protection of the rights and freedoms of others.

The most attention-seeking aspect of the limitation is not the closed catalogue of exceptions, but rather the standard of evaluating necessity, which is supposed to be appropriate for a democratic society. In practice, one may try to two interpret two very different standards out of Article 8 of the ECHR. The one used most often has an obvious flaw, which immediately renders the interpretation incorrect. Let us examine them briefly by formulating a generalized test for admissibility of the interference.

Suppose we are trying to determine whether the interference is admissible or not according to our standard of evaluating necessity. The first standard suggests to us the following "test." Check whether a country is a democratic state and check whether the government of this country was chosen within elections or another process which is commonly accepted as transferring social legitimization of power. For example, were the elections carried out according to the constitution of the country? If so, all 
instances of interference are justifiable under (2) within a certain catalogue described in the law. We must immediately note that such interpretation defies the purpose of the limitation. The test of admissibility implied by adopting this standard allows the government to introduce any changes, constitutional or unconstitutional, into the legal system and interfere as they please with the right to privacy of the citizens. Thus, after closer examination we must conclude that this interpretation is not consistent with Article 8 of the ECHR.

The "test" suggested by the second standard is to proceed as follows: for each instance of intended interference, check whether it is necessary for maintaining a democratic society. If not, for example, if a democratic society will be unharmed by the lack of privacy interference, but the changes would enhance policing and management of citizens, the interference is not admissible. If, however, the citizens' life, health or their capability of political engagement are at risk, the interference may be admissible. With this standard of evaluating necessity it becomes much harder to interfere with the privacy of the citizens. However, what is the position of foreigners within such regulations? Are the country's authorities obliged to consider them a part of a democratic society? Since human rights are by definition universal to all people, there is no justification to differentiate between foreigners and nationals in privacy protection despite the possibly ambiguous phrasing of Article 8 .

What are privacy laws then? Since hardly any legal system in the world allows people to act directly on their rights, privacy laws implement the protection measures for the right to privacy into the national legal system. As a result, in each country the right to privacy is protected differently within the law. There is an important fact we must note at this point. Namely, every person has the right to privacy regardless of whether the appropriate protective measures were implemented into a particular national legal system. If the national government does not implement regulations which allow proper protection of our rights, or if it limits our rights mentioned in the ECHR in an unjustifiable way, our rights are being infringed upon. Human rights cannot be taken away or limited and so when executing protection of those rights becomes hindered or impossible within the national legal system, it is the national government who is at fault.

However, in order to pinpoint the weak spots of national regulations, we need to have a solid understanding of the scope and nature of our fundamental rights. This understanding is often missing not only in the debates among the general population, but even in the doctrine of a given legal system. Let us now examine two examples of legal systems where the protection of the right to privacy may be impaired because of the unclear legal bases and the lack of agreement as to the nature of the right to privacy in the doctrine. The first example is that of the legal system of the United States of America, the other - of Poland as it functions within the European Union regulations. 


\section{COMPARING TWO LEGAL BASES FOR PRIVACY. THE US V. POLAND}

In the American legal tradition, the right to privacy has uncertain legal and philosophical foundations. ${ }^{1}$ The right to privacy is not directly mentioned in the United States Declaration of Independence from 1776 or the United States Constitution from 1778. Only the Amendments to the US Constitutions cover certain aspects of privacy protection. Most importantly, the $14^{\text {th }}$ Amendment prohibit the states from abridging the rights of the citizens. Keeping in mind the remarks from above, we must immediately ask whether this protection extends to the foreigners. The answer here is negative. Even though the USA was one of the original signatories of the Universal Declaration of Human Rights from 1948, there are no legal measures upon which a foreigner might act to execute direct protection related to their right described in Article 12 of the UDHR, according to which "no one shall be subjected to arbitrary interference with his privacy, family, home or correspondence, nor to attacks upon his honor and reputation. Everyone has the right to the protection of the law against such interference or attacks." Of course, there may exist other regulations of international private and public law which can be used as partial aid to the right to privacy. However, the protection is neither comprehensive, nor easily accessible.

The American doctrine provided little help to our understanding of the right to privacy. Historically one of the first American scholars to focus on the right to privacy was Prosser. ${ }^{2}$ The scope of his research, however, was limited to the analysis of case studies related to privacy, mostly in the context of business and civilian affairs. Moor ${ }^{3}$ enlisted some of the most popular theories of privacy which were used to interpret the American regulations concerning the infringement of the right to privacy. Among them is the non-intrusion theory of privacy, ${ }^{4}$ the theory of privacy as freedom to act, ${ }^{5}$ the theory of privacy as control of information, ${ }^{6}$ the theory of privacy as undocumented personal knowledge ${ }^{7}$ and the restricted access theory of privacy. ${ }^{8}$ Of all the mentioned theories only the last one seems to have survived the academic scrutiny.

${ }^{1}$ J. H. Moor, "The Ethics of Privacy Protection," Library Trends, Summer/Fall 1990, vol. 39, nos. $1-2$, pp. 69-82.

${ }^{2}$ W. L. Prosser, "Privacy,” California Law Review 1960, vol. 48, no. 3, pp. 383-423.

${ }^{3}$ Ibid., pp. 71-77.

${ }^{4}$ S. D. Warren, L. D. Brandeis, “The Right of Privacy,” Harvard Law Review 1980, vol. 4, no. 5, pp. 193-195.

5 J. H. Moor, “The Ethics of Privacy Protection," p. 74.

${ }^{6}$ C. Fried, D. Schoeman, Philosophical Dimensions of Privacy: An Anthology, New York 1984, p. 209; A. F. Westin, "Social and Political Dimensions of Privacy," Journal of Social Issues 2003, vol. 59, no. 2, pp. 431-453; A. F. Westin, "Privacy and Freedom," Washington and Lee Law Review 1968, vol. 25, issue 1, p. 166; E. Beardsley, "Privacy: Autonomy and Selective Disclosure," NOMOS: Yearbook of the American Society for Political and Legal Philosophy 1971, vol. 13: Privacy, pp. 56-70.

7 W. A. Parent, "Privacy, Morality, and the Law," Philosophy \& Public Affairs 1983, vol. 12, no. 4, pp. 269-288.

${ }^{8}$ A. L. Allen, Uneasy Access: Privacy for Women in a Free Society, Rowman \& Littlefield 1988; R. Gavison, "Privacy and the Limits of Law," The Yale Law Journal 1980, vol. 89, no. 3, pp. 421-471.; J. H. Moor, "The Ethics of Privacy Protection." 
The restricted access theory of privacy offers a useful heuristic that I shall refer to in this paper. According to the restricted access theory of privacy we can say that an individual or a group have privacy in a situation if and only if in that situation the individual or a group, or information related to them is protected from intrusion, observation and surveillance. This includes the interference by fellow citizens or by the state and its authorities. The question of whether we are due privacy in a given context can be paraphrased as the following question: is the given situation private or is it not?

Obviously, we must differentiate de facto privacy from a situation in which privacy is due. The situations which are private just by happenstance have been called "descriptively private" in the literature. ${ }^{9}$ Examples of such contexts are walking alone in the forest, being the only person on our town's market square, or being the last person to stay and work in our office. In a descriptively private situations we are alone, but we might just as well not be alone. Not every loss of a descriptively private situation violates our right to privacy. Conversely, not every situation where we do not in fact enjoy privacy is a situation where no expectation of privacy is in place. Such situations, the ones in which we are due privacy are referred to as "normatively private" situations, the normative aspect being either the legal, moral or pragmatic obligation. From now on I shall use this terminology to discuss the question of privacy in different contexts.

Let the other point for comparison be the legal regulations of Poland, a member the European Union since 2004 and a party to the ECHR since 1991. In the Polish national legal system, the protection of privacy stems from Articles 47 and 51 of the Constitution of the Republic of Poland from 1997. They introduce the following measures of privacy protection: ${ }^{10}$

1. the (universal) right to legal protection of private and family life, of honor and good reputation and making decisions about one's own personal life (Article 47);

2. the (universal) right to refrain from disclosing personal information about oneself, except in situations required by the statute (Article 51);

3. the prohibition concerning the public authorities to acquire, collect nor make accessible information on citizens other than that which is necessary in a democratic state ruled by law (Article 51);

4. the (universal) right of access to official documents and data collections concerning oneself, except in situations specified in the statute together with the right to demand the correction or deletion of untrue or incomplete information, or information acquired by means contrary to statute (Article 51).

However, although the Constitution requires that principles and procedures for collection of and access to information be specified by statute, the implementation of the constitutional rights is far from comprehensive. There has occurred the de facto

${ }^{9}$ H. T. Tavani, J. H. Moor, "Privacy Protection, Control of Information, and Privacy-Enhancing Technologies," ACM SIGCAS Computers and Society 2001, vol. 31, issue 1, pp. 6-11.

${ }^{10}$ As published in Dziennik Ustaw No. 78, item 483. 
division between the right to privacy as infringed by the fellow citizens and business agents and the right to privacy as infringed by the state. And although the Polish legal system is equipped in more or less sufficient institutions which can address the former, there are little to no protective measures which can be used in case of the latter.

In Poland the Inspector General for Personal Data Protection (GIODO) is responsible for supervising the compliance of data processing with the provisions on the protection of personal data, initiating the steps necessary to improve the protection of personal data, issuing administrative decisions and considering complaints with respect to the enforcement of the provisions on the protection of personal data, based on the provisions of the Act of 29 August 1997 on the Protection of Personal Data. ${ }^{11}$ Moreover, the problem of preventing illegal mass surveillance or educating the citizens about their rights to privacy was not at all addressed during the meeting of the data protection authorities of the V4 counties which took place in March of 2017. ${ }^{12}$

\section{THE PRIVACY OF FOREIGNERS}

How are foreigners different when it comes to privacy? Or, using the terminology introduced in the previous section, is it possible to justify that certain situations are (normatively) private for a citizen of a given country but not (normatively) private for a foreigner? Generally speaking, there are no limitations on what kind of information may be required of a foreigner who tries to enter, exit or transit through the territory of a given country. There are no situations which could be defended as legally private as long as we are not under the jurisdiction of our own national constitution. Even the fundamental human rights cannot protect us from obeying the ground-level regulations, like airport security protocols, visa application requirements, etc. Either we provide the required information and comply with the infringement on our right to privacy, or we may be denied access to the country's territory, institution or service.

Consider the requirements of visa applications and the searches conducted at the entrance to the territory. The "Family Details" section in the Indian visa application requires that a woman provides information about the number of pregnancies she had, the number of births resulting from those pregnancies and specifying how many children were born alive. ${ }^{13}$

To use another example, the policy of "extreme vetting" adopted in the USA by the Trump administration required tourists and other visitors to hand in their passwords for online services like email, Facebook or other social media on demand of the border officer at the risk of being denied access to the country. Moreover, any

${ }^{11}$ The Act of 29 August 1997 on the Protection of Personal Data - Ustawa z dnia 29 sierpnia $1997 \mathrm{r}$. o ochronie danych osobowych (t.j. Dz. U. z 2015 r., poz. 2135).

12 The information about the agenda can be found at http://www.giodo.gov.p1/259/id_art/860/j/en [access: 12.12.2017].

${ }^{13}$ See: https://www.travisa.com/india-visaguide.html [access: 1.01.2017]. 
attempt to protect personal data may be interpreted as a "probable cause" for an extended border search. ${ }^{14}$ The border control officers may also search the entrant's electronic devices, hard disks and memory cards. The number of conducted searches increased already in 2016 when it grew to 24,000 (from nearly 5,000 in 2015). ${ }^{15}$

How do those regulations against the privacy of foreigners compare to measures taken against the privacy of the citizens? The American citizens are protected from unjustified searches under the Amendment to the US Constitution. Even though the practice indicates that the US nationals are also subjected to governmental surveillance, the programs of mass surveillance are widely considered illegal and the citizens may rely on the exclusionary rule within the doctrine of the "fruit of the poisonous tree" when in the court of law. ${ }^{16}$ This is just but one example of a double standard in privacy protection in cases of foreigners and the country's citizens. The most puzzling question now is the following: why do we allow such double standards to persist? How are foreigners different from the citizens when it comes to the scope of situations of limited privacy?

In my opinion the answer to these questions relies on our understanding of the "state of emergency" situations and our propensity to treat certain groups of people, in particular the foreigners, but also other groups, as a threat to the state's security. The next sections explain what I mean by the "state of emergency" and how it can be completely unrelated to the public safety.

\section{WHO CAUSES THE "STATE OF EMERGENCY"?}

The "state of emergency" situation to which I refer in this paper differs from the actual national state of emergency or a situation of national crisis. The latter form of the state of emergency or crisis is proclaimed across the country in a situation of a natural disaster, civil unrest or armed conflict. Generally speaking, the motivation behind the national state of emergency is to empower the government authorities to perform actions which would otherwise be unavailable to them, including the power to perform additional controls, surveillance and other forms of limiting the citizen's right to privacy. However, introducing a nation-wide state of emergency is problematic. For most countries taking such a drastic measure is a history-making event. Therefore, governments try to use potential threats to either the state itself or to the public safety to increase the scope of extraordinary situations, which can justify taking extra actions, otherwise legally unavailable to the government. And so

\footnotetext{
${ }^{14}$ See: https://www.theguardian.com/us-news/2017/apr/09/uk-tourists-to-us-may-get-asked-to-hand-inpasswords-or-be-denied-entry [access: 12.12.2017].

${ }^{15}$ See: https://www.voanews.com/a/are-password-requests-at-border-legal/4009285.html [access: 12.12.2017].

${ }^{16}$ R. M. Pitler, "The Fruit of the Poisonous Tree Revisited and Shepardized," California Law Review 1968 , no. 57, pp. 580-581.
} 
by the "state of emergency" I understand any situation in which the government authorities limit the fundamental rights of an individual, be it the country's national or a foreigner, due to the alleged, but not proven to be actual, threat related to either the person's belonging to a certain social category, or the type of service that the person is trying to use.

The potential reasons for introducing situational "states of emergency" are not limited to terrorist threats to the public security. In the most general scenario, they can range from being a member of a group with propensity towards tax fraud to taking part in peaceful protests against issues related to national or international politics, declaration of war, harmful climate agreements etc. Even before the era of mass surveillance technologies, the label of a potential threat to the national security was put on people like Louis Armstrong, Nat King Cole and Frank Sinatra, who were subsequently surveilled by the American Federal Bureau of Investigation. ${ }^{17}$

According to Bauman ${ }^{18}$ the ultimate goal of introducing the "states of emergency" is to win control over the governed population. By pointing to the common enemy of the nation, the government is able to single out any individual as a potential threat and neutralize their political or economic influence. The mechanism of social division supports this process by providing new features which serve as foundations for evaluating a given individual as a threat to the security, the traditions or customs, the national heritage or the financial well-being of the state. Such features include in particular gender, sexual orientation, foreign origin or ethnicity, living in poverty, etc.

Let us recall a case described by Niklas et al., ${ }^{19}$ which concerns the Polish national-wide assistance tool aimed at the unemployed citizens. The initial purpose of the assistance tool was to assess the chances of a person registered in the labor office at the job market and customize the office's assistance to fit their individual needs. Each person among the registered unemployed was categorized as either an A, a B or a $\mathrm{C}$, depending on the total points for the answers in a questionnaire given to them at the moment of registration. The first category included those who were likely to find a new position without the assistance of a labor office but used it to browse through the recent post openings. B-category included people who were employable, but less likely to find a job offer on current listings of open post available to a labor office. The third category, C, included those deemed "permanently away from the job market," or in other words, unemployable. Falling into the third category proved surprisingly easy and was not at all based on person's availability, skill, education or qualification. For example, a woman over 30 with an ill person under her care would qualify as a $\mathrm{C}$. The labor office would not use its resources to help a person who was a $\mathrm{C}$ but would rather direct all efforts towards those who are easier to help, mostly those in A-category. Such procedure was indeed very effective but failed to help those whose well-being lay in the heart of social services, that is those who cannot deal with

17 A. W. Lehren, "Jazz and the FBI: Guilty Until Proven Innocent," JazzTimes, https://jazztimes. $\mathrm{com} /$ features/jazz-and-the-fbi-guilty-until-proven-innocent/ [access: 12.12.2017].

18 Z. Bauman, D. Lyon, Liquid Surveillance: A Conversation, Malden, MA 2013.

19 J. Niklas, K. Sztandar-Sztanderska, K. Szymielewicz, Profiling the Unemployed in Poland: Social and Political Implications of Algorithmic Decision Making, Warsaw 2015. 
a problem without assistance. An argument for following up on the categorization and cutting off those in categories of B and C from certain (or sometimes even all) opportunities available to the A-rated was similar to any other "state of emergency" argument. Namely, people who have lower chances of finding a stable working position can constitute a threat to national budget. The process of imposing limitations on social service in this case is similar to the process of restricting rights of the foreigners - based on the premise that a certain feature of a given individual makes them a threat to a the agenda of a certain branch of the national government, an individual is categorized as a threat and denied access either to the territory, or to a service otherwise accessible without restrictions.

\section{SUMMARY}

In this paper I argued that normalizing infringement on the privacy of foreigners, for example due to a certain recurrent "state of emergency," leads to weakening of the execution of privacy protection by means of ground-level regulations, that is the protocols and laws which implement exceptions to the privacy protection. In order to make my case I related the right to privacy understood as a fundamental right common to all people to the national and international privacy laws, which are supposed to protect the right to privacy and further specify how the right is understood within a given legal and cultural tradition. The chosen examples were those of Poland and the United States of America.

The following section concerning the treatment of foreigners used explored the problem of privacy infringement in the context of visa applications, border controls and tourist surveillance. The partial argument was that foreigners are treated differently than the country's nationals in the sense that they cannot summon the same protective measures against the interference with their privacy. A common justification for stripping the foreigners of their privacy is that their presence causes a certain kind of "state of emergency."

This justification normalizes the infringement on the privacy of the foreigners, and it turn contributes to the development of surveillance tools which are later used against the citizens when the appropriate "state of emergency" becomes available as a justification for infringement. The examples given were the "states of emergency" related to extra financial costs that the individual causes the state as they become unemployed or require social aid.

This process of introducing various "states of emergency" represents the way in which the measures taken against the foreigners can weaken the rule of law within the state itself by turning the surveillance technology against the best interest of the citizens. 


\section{BIBLIOGRAPHY}

\section{Books and Articles}

Allen, A. L., Uneasy Access: Privacy for Women in a Free Society, Rowman \& Littlefield 1988.

Bauman, Z., Lyon, D., Liquid Surveillance: A Conversation, Malden, MA 2013.

Beardsley, E., "Privacy: Autonomy and Selective Disclosure," NOMOS: Yearbook of the American Society for Political and Legal Philosophy 1971, vol. 13: Privacy, pp. 56-70.

Fried, C., Schoeman, D., Philosophical Dimensions of Privacy: An Anthology, New York 1984.

Gavison, R., "Privacy and the Limits of Law," The Yale Law Journal 1980, vol. 89, no. 3, pp. 421-471.

Moor, J. H., "The Ethics of Privacy Protection," Library Trends, Summer/Fall 1990, vol. 39, nos. 1-2, pp. 69-82.

Niklas, J., Sztandar-Sztanderska, K., Szymielewicz, K., Profiling the Unemployed in Poland: Social and Political Implications of Algorithmic Decision Making, Warsaw 2015.

Parent, W. A., "Privacy, Morality, and the Law," Philosophy \& Public Affairs 1983, vol. 12, no. 4, pp. 269-288.

Pitler, R. M., "The Fruit of the Poisonous Tree Revisited and Shepardized," California Law Review 1968, no. 57, pp. 580-581.

Prosser, W. L., "Privacy,” California Law Review 1960, vol. 48, no. 3, pp. 383-423.

Tavani, H. T., Moor, J. H., "Privacy Protection, Control of Information, and PrivacyEnhancing Technologies," ACM SIGCAS Computers and Society 2001, vol. 31, issue 1, pp. 6-11.

Warren, S. D., Brandeis L. D., “The Right of Privacy,” Harvard Law Review 1980, vol. 4, no. 5, pp. 193-195.

Westin, A. F., "Social and Political Dimensions of Privacy," Journal of Social Issues 2003, vol. 59, no. 2, pp. 431-453.

Westin, A. F., "Privacy and Freedom," Washington and Lee Law Review 1968, vol. 25, issue 1 .

\section{Legal Documents}

The Act of 29 August 1997 on the Protection of Personal Data - Ustawa z dnia 29 sierpnia 1997 r. o ochronie danych osobowych (t.j. Dz. U. z 2015 r., poz. 2135). 


\section{Online Resources}

https://jazztimes.com/features/jazz-and-the-fbi-guilty-until-proven-innocent/ [access: 12.12. 2017].

https://www.voanews.com/a/are-password-requests-at-border-legal/4009285.html [access:

12.12.2017].

https://www.theguardian.com/us-news/2017/apr/09/uk-tourists-to-us-may-get-asked-to-hand-in-passwords-or-be-denied-entry [access: 12.12.2017].

https://www.travisa.com/india-visaguide.html [access: 1.01.2017].

http://www.giodo.gov.pl/259/id_art/860/j/en [access: 12.12.2017]. 